
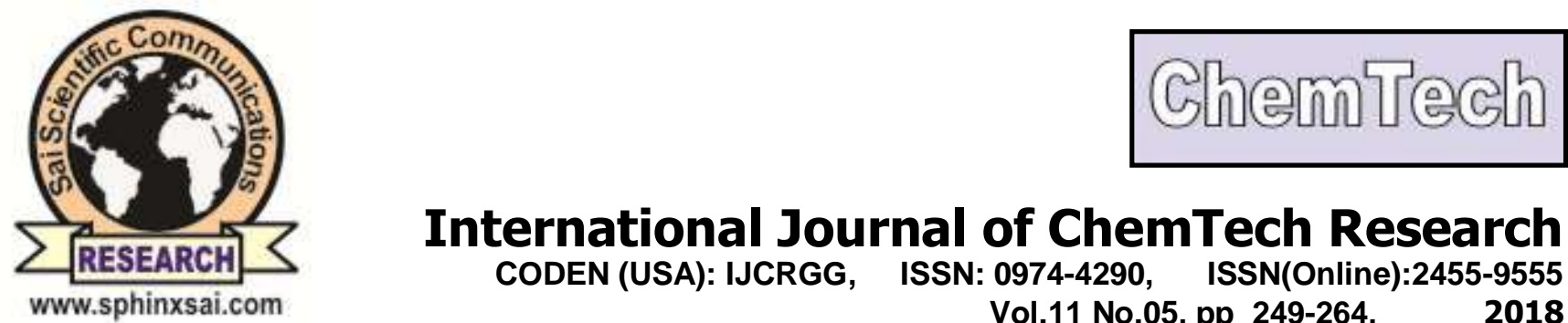

International Journal of ChemTech Research CODEN (USA): IJCRGG, ISSN: 0974-4290, ISSN(Online):2455-9555

Vol.11 No.05, pp 249-264,

2018

\title{
Design of A Modular Filtration-Adsorption System for Removal of Methylene Blue and Turbidity using Activated Carbons and A Sand-Gravel-Anthracite Filter
}

\author{
Candelaria Tejada-Tovar ${ }^{1}$, Angel Villabona-Ortíz ${ }^{2}$, Luis Romero-Murillo ${ }^{3}$, \\ Gabriel Florez-Madrigal ${ }^{4}$, Diofanor Acevedo ${ }^{\star 5}$
}

${ }^{1,2,3,4}$ Faculty of Engineering, Chemical Engineering program, Research Group IDAB, University of Cartagena Av. El Consulado, St. 30 No. 48-152. Colombia.

${ }^{1,5}$ Faculty of Engineering, Research Group Innovation, Agricultural and Agro-industrial Development, University of Cartagena Av. El Consulado, St. 30 No. 48-152. Colombia.

\begin{abstract}
The presence of methylene blue (MB) and turbidity in water bodies resulting from industrial effluents and urban runoffs cause concern due to their harmful effects on health. Therefore, the present research developed and analyzed the design of a continuous modular plant for water treatment through adsorption and filtration operations for use in the removal of methylene blue and bentonite, respectively, using sand, gravel and anthracite filter media and activated carbon as adsorbent media. The different operating variables of the processes by means of accessories such as valves and flow calibrators and the models that best fitted the optimal operation of the plant were determined. The most influential design parameters were found to be length, column diameter and flow rate. In the adsorption tests it was obtained that the most influential parameter is the filling height, establishing the response surface methodology the optimal adsorption conditions efficiently, adjusting the experimental data to the Yoon-Nelson model with R2 $=0.97$ with a removal percentage $\mathrm{R}(\%)=79.74 \%$. The most influential parameter in filtration was the stratification of the bed, proving that the rapid filtration rate with the filling height conditions in the established range significantly influences, with Deb's equation being the one that best adjusts the dynamic behavior of this process with $\mathrm{R}^{2}=0.98$ and a removal percentage of $95.82 \%$. The use of a modular filtrationadsorption system for removal of methylene blue and turbidity using activated carbons and a sand-gravel-anthracite filter, respectively, is an economical alternative to conventional water treatments.
\end{abstract}

Keywords : Methylene blue, bentonite, Yoon-Nelson model, Deb equation.

\section{Introduction}

Industrial development and population growth affect the quality of water bodies. Effluents containing dye discharges from the textile, paint, paper, plastics, cosmetics and food processing industries have become a major concern as industries produce more than 700,000 tons of dye per year, of which $50 \%$ is absorbed in

International Journal of ChemTech Research, 2018,11(05): 249-264.

DOI= http://dx.doi.org/10.20902/IJCTR.2018.110528 
surface water as well as urban runoff with a high rate of turbidity [1]. Methylene blue (MB) is a colorant commonly used in the industry for dyeing cotton, silk and wood, it is not considered toxic, but its presence for long periods of time can cause several harmful effects for humans and some animals. Inhalation may cause difficulty and agitation in breathing, while ingestion may cause nausea, vomiting and mental confusion [2,3].

In the treatment of drinking water, physical-chemical methods are used such as flocculation, filtration, ion exchange, irradiation, adsorption by activated carbon, among others, these processes are very costly to implement [4]. Researchers showed that the effectiveness of experimental filtration studies depends on the ability to evaluate the results in the initial runs and thus be able to modify the operation in the subsequent runs; in order to facilitate the process, an experimentation methodology is proposed supported by the use of shallowbed filters, oriented towards the analysis of the factors that the designer and operator can control: Filtration rate, medium type and size, bed thickness, type and dose of reagent [5]. Also, the application of anthracite and sand filters was evaluated in order to determine the correct combination of conditions necessary to obtain satisfactory results; it was also carried out in pilot plants in relation to the design of the treatment of new sources, as well as the reconditioning of existing units, using filters of $3 \mathrm{ft}$ in diameter and $11 \mathrm{ft}$ in height [6].

Adsorption studies of methylene blue have been conducted using rice husk as a biosorbent as reported by Moreno et al., [2] and Villada et al., [7], commercial activated carbon as investigated by Garcia et al., [8], maize tuza consistent with that reported by Hormaza et al., [9], activated carbon synthesized from Pongamia pinnata according to Islam et al., [10] activated carbon with magnetic charge as reported by Angin et al., [11]; also heterogeneous photocatalysis with $\mathrm{TiO}_{2} / \mathrm{UV}$ as reported by Clavijo-Penagos [12] finding that the most influential variable in the continuous adsorption process is bed height and that the sorbent media are suitable for removal of the contaminant in aqueous solution. On the other hand, the influence of flow control (declining and constant rate) on the filtration of drinking water from the Cauca River, Colombia has been studied; finding that the rate of decrease presents the best turbidity removal levels in comparison to the constant velocity [13]. Also, the filtering capacity of five commercial activated carbons was studied to determine bed saturation, variations in pressure drop, the removal performance of suspended organic matter, the time and backwash rate of filters and the expansion of the optimal filter bed; it was found that activated carbons produce more water-soluble substances, due to their high volatile matter content and low hardness, the most influential factor in the process being the particle size of the adsorbent [8].

In this sense, the present research aimed to design and construct a modular system on a pilot scale to evaluate the use of activated carbon in the adsorption of methylene blue and a turbidity removal system to clarify the water using a sand-anthracite-gravel filter in a continuous system.

\section{Pilot plants:}

Mathematical models may indicate trends and relationships, but they are not sufficient to predict quantitative outcomes. In this context, pilot plants, a physical model, are responsible for integrating the interactive behavior of a multitude of variables to produce associated results that can be accurately measured. A pilot plant is a prerequisite for a large-scale, economical plant design necessary for efficient operation [14]. Trials at pilot plants should be carefully planned, designed and monitored to obtain conclusive results necessary for the design development and performance prediction of future full-scale treatment plants. Due to the reliable operating system and possible unavailability of pumps with low discharge rates, these should be avoided whenever possible, except for raw water lifting.

Landfills or small holes are suitable devices for flow control. For its part, the use of small clamps or valves is not recommended, as they are quickly clogged and therefore do not maintain a constant flow rate. The diameter of the filter columns should not be too small to reduce side wall short-circuit in pilot filters; the recommended ratio for dcolumn/dmedia=25 [15]. The hydraulic load on the pilot unit must be close to the highest recommended value, e. g. slow sand filter units must run at $0.2 \mathrm{~km} / \mathrm{h}$, which will reduce the filter run time and allow more filter runs within a certain period of time. The size of the pilot plant units should not be too small and know the recommended minimum flow rate mentioned above of $0.5 \mathrm{~L} / \mathrm{min}$. The diameters listed in Table 1 are recommended: 
Table 1. Operation variables in pilot filtration plant

\begin{tabular}{|l|l|l|}
\hline \multicolumn{3}{|c|}{ Pipe minima: Roughing filter with rising flow } \\
\hline For VF min. $=0.6 \mathrm{~m} / \mathrm{h}$ & Fmin. $=30 \mathrm{~cm}$ & $\mathrm{Q}=0.61 / \mathrm{min}$. \\
\hline slow sand filter & Fmin. $=50 \mathrm{~cm}$ & $\mathrm{Q}=0.71 / \mathrm{min}$. \\
\hline For VF min. $=0.2 \mathrm{~m} / \mathrm{h}$ &
\end{tabular}

\section{Experimental}

For the construction of the modular adsorption-filtration plant, pipes $(0.5-1)$ in PVC, pipe (0.5 in) CPVC, angles of 1.5 in of iron, acrylic $4.4 \mathrm{~cm} \mathrm{Di}$, acrylic $6 \mathrm{~mm}$ thick, joints, adapters (female - male) of PVC $(0.5$ - 1) in, joints, adapters (male) of CPVC 0.5 in, sieve \# $(8-16-30)$ were used. Spectrumlab 54 UV-VIS Spectrophotometer for determining the initial and final concentration of methylene blue in synthetic waters and a Turbidity meter with Fast Tracker Technology EPA compliant for determining the initial and final concentration of bentonite in synthetic waters. The experimental design of the adsorption plant was carried out by establishing as dependent variables: the concentration of the dye ( $\mathrm{ppm})$ the quantity of the dye removed (\%), as independent variables: the height of the bed $(\mathrm{cm})$ and flow rate $(\mathrm{ml} / \mathrm{min})$, as intervening variables: the $\mathrm{pH}$ of the solution, the packing density $\left(\mathrm{g} \mathrm{L}^{-1}\right)$ and the particle size $(\mathrm{mm})$. For the filtration design, turbidity (NTU) and the amount of particles removed (\%) were established as dependent variables, bed stratification as an independent variable, and flow velocity $(\mathrm{ml} / \mathrm{min})$, particle diameter $(\mathrm{mm}), \mathrm{pH}$, packing density $\left(\mathrm{g} \mathrm{L}^{-1}\right)$ and particle size $(\mathrm{mm})$ as intervening variables.

\subsection{Identification of design and operation variables}

In the modular adsorption-filtration plant, a gravity flow system was used, where rate and level remain constant, causing turbid or polluted water to flow from a feed tank and pumped to the distribution tank, where a constant level is maintained by overflow; water was then distributed by gravity to the two columns, where the filtration or adsorption process was carried out independently. Finally, the water is received in an accumulation tank for each column and its subsequent analysis [6]. The calculation of the ratio of column length (L) to bed diameter (D) is $\mathrm{L} \mathrm{D}^{-1}$ [8]. Similarly, the ratio $\mathrm{L}: \mathrm{H}_{\mathrm{L}}$ was calculated, where $\mathrm{H}_{\mathrm{L}}$ is the height of the bed and flow rate $(\mathrm{q})$ was calculated using equation 1 where $\mathrm{A}$ is the area of the column and $\mathrm{v}$ is the filtration rate.

$q=A^{*} V$

$q=\pi * D^{2} * v$

The purpose of the distribution tank is to keep the pressure head constant by overflow, in order to maintain the similar flow rate in each column. For the calculation of the total volume $\left(\mathrm{V}_{\mathrm{td}}\right)$ of the distribution tank, the volume necessary to maintain the constant level $\left(\mathrm{V}_{\mathrm{n}}\right)$ is taken into account, taking into account Equations 3 and 4 where $h$ is the height, $\mathrm{L}$ is the lake, and a, b and $\mathrm{c}$ are the three-dimensional measurements. The collection tank was designed and built in order to receive the treated water for later analysis and transfer it to the storage tank, its schematization is shown in Fig. $1 \mathrm{~b}$.

$V_{t d}=(L+b) * a *(h+c)$

$V_{n}=L+a+h$

The flow calibrator was used to know the flow rate of each of the columns, according to the opening of the gate valves, taking as a basis of calculation one (1) min, thus identifying the desired flow rate. It was designed following Equation 5 where $\mathrm{v}$ is the volume of the cylinder $\left[\mathrm{cm}^{3}\right], \mathrm{h}$ is the height of the gauge $[\mathrm{cm}], \mathrm{t}$ is the calibration time[min].

$q=D^{2} * \frac{h}{t} \frac{\pi}{4}$ 


\subsection{Calibration of accessories and hydraulics}

The calibration for the pump was performed by priming the pump, eliminating air bubbles retained in the piping line. For this purpose, the fluid to be treated was circulated according to the process to be applied, by means of the plant's priming valve. The calibration of the flow meter was performed maintaining the level and rate constant with all valves closed; proceeding as follows to calibrate the flow rate in column 1, the valve was opened that allows the flow rate between the flow meter and the valve that controls the flow rate to column 1 , the latter being proportionally controlled until the desired flow rate is obtained, by means of the reading on the flow rate scale, based on 1 minute. In order to calibrate the flow rate in column 2 (C2), the same procedure was used: by closing the valve that controls the flow rate to column 1 , by opening the valve that allows the flow meter to pass through to the valve that allows the flow rate to column 2, and by operating it proportionally. The calibration of the pilot plant's hydraulic system for water treatment in a continuous system (adsorption filtration) was maintained, ensuring that the outlet flow in the valves that allow the passage to the columns (V4 and V5) was equal to the outlet flow in the columns (V11 and V12) respectively, verifying the level of C1 and $\mathrm{C} 2$ to verify that the system is in a stationary state.

Table 1. Central compound design: $2^{2}+$ star

\begin{tabular}{|c|r|r|r|}
\hline & \multicolumn{3}{|c|}{ Dominio experimental } \\
\cline { 2 - 4 } Experimental factors & Minimum & Central & Maximum \\
\hline Flow $\left(\mathrm{mL} \mathrm{s}^{-1}\right)$ & 0.4 & 0.5 & 0.6 \\
\hline Height $(\mathrm{cm})$ & 5 & 10 & 15 \\
\hline
\end{tabular}

\subsection{Dynamic behaviour of the filter column}

The hydraulic supply for the filtration column is drinking water with bentonite prepared by the addition of two $1.25 \mathrm{~g}$ samples of bentonite to two $1 \mathrm{~L}$ containers of tap water, with continuous agitation for 30 min to achieve uniform dispersion of the particles, with a $24 \mathrm{~h}$ period for hydration. The solutions were diluted in $19 \mathrm{~L}$ each and then mixed; although this model does not represent the actual water of any city, it is a stable suspension that can be used to study the coagulation mechanism $[15,16]$. For the collection of data in the fixed bed column packed with sand and anthracite in a continuous system, its operation and calibration were initially verified by conducting experiments to remove bentonite in synthetic waters, for which the following experimental design was carried out.

The modeling of the dynamic behavior of the column packed with sand and anthracite was done using the mathematical models of Mintz and Krishtul, Deb, and Adin and Rebhun. For the design was established for sieves number 4, 8, 16 and 30 particle diameters of 4.7498, 2.36, 0.88646 and $0.6 \mathrm{~mm}$ respectively, using Taylor series sieves and establishing the diameters of the materials to be used during the stratification of the packed bed and the amount of mass (g) to carry out the unitary filtration operation in accordance with Table 3.

Table 3. Granulometric analysis of filter media

\begin{tabular}{|c|c|c|c|c|c|}
\hline \multicolumn{2}{|c|}{ Gravel } & \multicolumn{2}{c|}{ Sand } & \multicolumn{2}{c|}{ Anthracite } \\
\hline \# Sieve & Weight (g) & \# Sieve & Weight (g) & \# Sieve & Weight (g) \\
\hline 4 & 86 & 16 & 293.6 & 8 & 15.2 \\
\hline 8 & 438.9 & 30 & 363.2 & 16 & 246 \\
\hline 16 & 65.6 & & & 30 & 23.3 \\
\hline Total & 590.5 & Total & 656.8 & Total & 284.5 \\
\hline
\end{tabular}

The amount of material $(\mathrm{g})$ was then calculated per bed volume $\left(\mathrm{cm}^{3}\right)$; finally, the filtering material was stratified to establish $1.71,1.92$ and $1.23 \mathrm{~cm}^{3}$ of gravel, sand and anthracite accordingly. For the collection of experimental data in the unitary filtration operation, 3 experiments were determined, and the importance of stratification was thus verified. In addition, the experimentation was established where a greater percentage of removal was obtained, and the stratifications of the experiments carried out during sampling can be observed in Table 4. 
Table 4. Experimental stratifications for filtration

\begin{tabular}{|c|c|c|}
\hline \multicolumn{3}{|c|}{ Stratification for filtration experiments } \\
\hline & Anthracite $(\mathbf{c m})$ & $\begin{array}{c}\text { Sand } \\
(\mathbf{c m})\end{array}$ \\
\hline Experimentation 1 & 17.50 & 5.8 \\
\hline Experimentation 2 & 7.80 & 15.5 \\
\hline Experimentation 3 (optimal) & 16.6 & 6.7 \\
\hline
\end{tabular}

\section{Results and discussions}

\subsection{Identification of design variables}

In order to establish the dimensions, characteristics and construction parameters of the modular plant, it was necessary to identify the design and operation variables for the optimal functioning of the adsorption and filtration system at laboratory scale. For this reason, the conceptual design of the filtering and adsorption units was carried out by calculating the L/D ratio, which relates the length of the Columba $(\mathrm{L})$ with respect to the diameter of the bed (D) taking into account the provisions of Garcia and other $\mathrm{L} / \mathrm{D}=12$. It is also established that the height of the packed bed by the ratio is $\mathrm{L} / \mathrm{H}_{\mathrm{L}}=2.5714$, where $\mathrm{HL}$ is the height of the packed bed. As the diameter of the columns is $4.4 \mathrm{~cm}$, we obtain the length data of the column $(\mathrm{L})$ and the packed bed $\left(\mathrm{H}_{\mathrm{L}}\right)$ have values of 5.28 and $20.5 \mathrm{~cm}$, respectively. For the design of the distribution tank we proceeded based on equation 3, taking as design values those stipulated in Table 1, establishing for $\mathrm{V}_{\mathrm{n}}=5 \mathrm{~L}\left(5000 \mathrm{~cm}^{3}\right), \mathrm{h}=15 \mathrm{~cm}$ and $\mathrm{a}=13 \mathrm{~cm}, \mathrm{~b}=5 \mathrm{~cm}$ and $\mathrm{c}=4 \mathrm{~cm}$. Finally from Equation 6 you have to:

$L=\sqrt{\frac{V_{n}}{h \llbracket a}}=\sqrt{\frac{5000 \mathrm{~cm}^{3}}{15 \mathrm{~cm} \square 3 \mathrm{~cm}}}=25.64 \mathrm{~cm}$

Replacing in Equation 3 we have to $\mathrm{V}_{\mathrm{td}}=8,717 \mathrm{~L}$. The collection tanks were designed to scale 1:1 of the distribution tank, obtaining a height $\mathrm{H}=20 \mathrm{~cm}$, length $\mathrm{L}=25.64 \mathrm{~cm}$, depth $\mathrm{a}=17 \mathrm{~cm}$ and total volume $\mathrm{Vtd}=8.71 \mathrm{~L}$. The flow rate of the flow meter was obtained by equation 5, based on a calculation of 1 minute, with the following results from Table 5:

Table 5. Flow Calibrator Scale

\begin{tabular}{|c|c|c|c|c|c|}
\hline Flow $\left(\mathrm{mL} \mathrm{s} \mathbf{s}^{-1}\right)$ & $\begin{array}{c}\text { Height } \\
(\mathrm{cm})\end{array}$ & $\begin{array}{c}\text { Flow (mL s } \\
1)\end{array}$ & $\begin{array}{c}\text { Height } \\
(\mathrm{cm})\end{array}$ & $\begin{array}{c}\text { Flow }_{(\mathrm{mL} \mathrm{s}}^{-} \\
\left.{ }^{-}\right)\end{array}$ & $\begin{array}{c}\text { Height } \\
(\mathbf{c m})\end{array}$ \\
\hline & & 0.9 & 3.6 & 1.8 & 7.1 \\
\hline 0.1 & 0.4 & 1 & 4 & 1.9 & 7.5 \\
\hline 0.2 & 0.8 & 1.1 & 4.3 & 2 & 7.9 \\
\hline 0.3 & 1.2 & 1.2 & 4.7 & 2.1 & 8.3 \\
\hline 0.4 & 1.6 & 1.3 & 5.1 & 2.2 & 8.7 \\
\hline 0.5 & 2 & 1.4 & 5.5 & 2.3 & 9.1 \\
\hline 0.6 & 2.4 & 1.5 & 5.9 & 2.4 & 9.5 \\
\hline 0.7 & 2.8 & 1.6 & 6.3 & 2.5 & 9.9 \\
\hline 0.8 & 3.2 & 1.7 & 6.7 & & \\
\hline
\end{tabular}

\subsection{Design dimensions of the modular adsorption - filtration plant}

In order to dimension the mechanical structure that supports the modular adsorption-filtration plant described in Figure 1 and 2, a scale of 1:3 was taken into account for the height, on the length of the columns, obtaining $180 \mathrm{~cm}$ long, $60 \mathrm{~cm}$ wide and $160 \mathrm{~cm}$ high. The feeding tank with $50 \mathrm{~L}$ capacity has an inner diameter of $35 \mathrm{~cm}, 30 \mathrm{~cm}$ inner diameter and $55 \mathrm{~cm}$ height. 


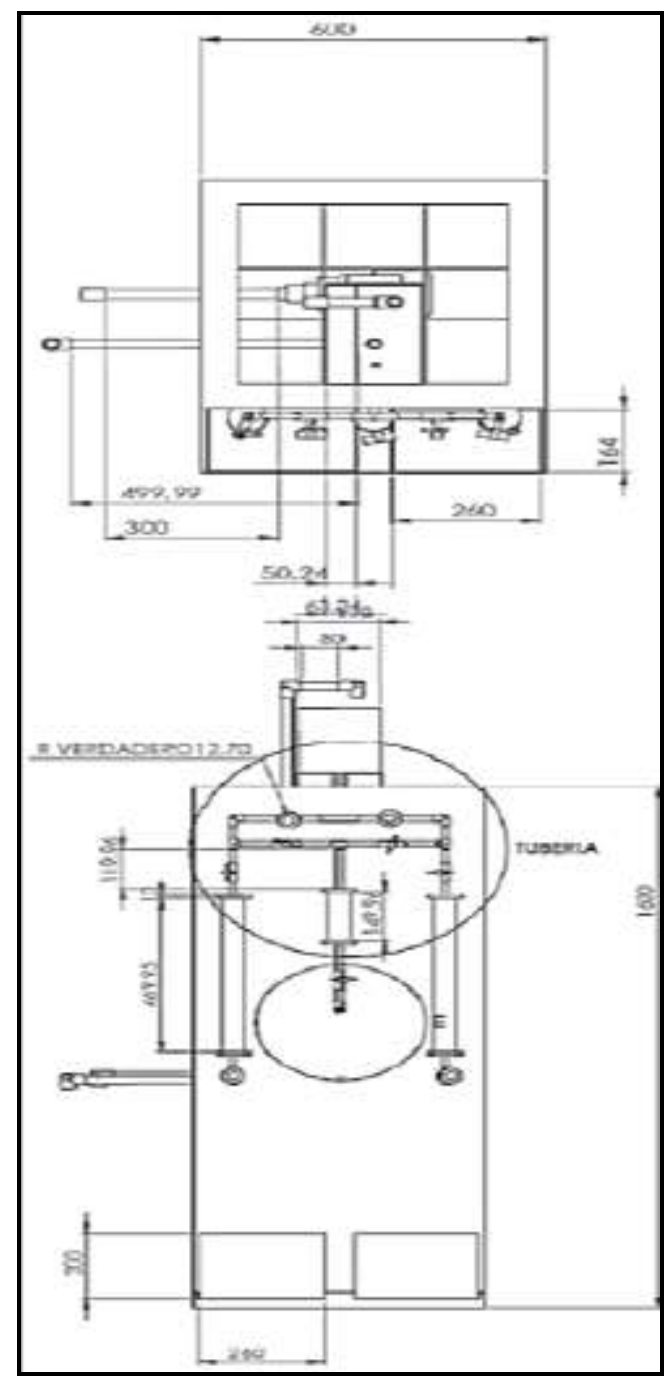

Figure 2. P\&ID modular plant for water treatment in continuous systems (absorption - filtration)

Table 6. Identification and characteristics of modular plant for water treatment in continuous adsorption-filtration system

\begin{tabular}{|l|l|l|}
\hline Symbology & Name & \multicolumn{1}{c|}{ Characteristic } \\
\hline TK-1 & T de alim & Feeds water to treat, this starts the process \\
\hline P-1 & B perifer & Suction from TK-1; download in TK-2 \\
\hline TK-2 & T de dist & Maintains constant level and distributes fluid to C-1 and C-2 \\
\hline V-1 & V globo & Allows the pump to be primed for operation \\
\hline V-2 & V globo & Adjustable pump flow rate to TK-2 \\
\hline V-3 & V globo & Allows adjustment of the recirculation from TK-2 to TK-1 \\
\hline V-4 & V comp & Allows to control the flow rate towards C-1 \\
\hline V-5 & V comp & Allows to control the flow rate towards C-2 \\
\hline V-6 & V globo & Allows fluid to flow into R-1 from V-4 \\
\hline V-7 & V globo & Allows fluid to flow into R-1 from V-5 \\
\hline V-8 & V globo & Allows fluid flow to C-1 from V-4 \\
\hline V-9 & V globo & Allows fluid to flow into C-2 from V-5 \\
\hline R-1 & M flujo & Calculate flow rate based on one minute \\
\hline V-11 & V comp & Allows controlling the output flow of C-1 \\
\hline V-12 & V comp & Allows controlling the output flow of C-2 \\
\hline TK-3 & T recol & Collects fluid out of C-1 \\
\hline TK-4 & T recol & Collects fluid out of C-2 \\
\hline TK-5 & T almac & Stores the collected material in TK-3 and TK-4 \\
\hline
\end{tabular}


The $8.8 \mathrm{~L}$ distribution tank and the collection tanks were $26 \mathrm{~cm}$ long, $17 \mathrm{~cm}$ wide and $20 \mathrm{~cm}$ high. The dimensions of the level area with $5 \mathrm{~L}$ capacity were $26 \mathrm{~cm}$ long, $12 \mathrm{~cm}$ wide and $15 \mathrm{~cm}$ high. Table 6 shows the nomenclature of the accessories that make up the modular plant for water treatment in a continuous adsorptionfiltration system corresponding to P\&ID. For its part, the $2 \mathrm{~L}$ discharge area was $26 \mathrm{~cm}$ long, $5 \mathrm{~cm}$ wide and $15 \mathrm{~cm}$ high. The filter-adsorption columns had an external diameter $\mathrm{DE}=4.7 \mathrm{~m}$, internal diameter $\mathrm{DI}=4.4 \mathrm{~cm}$ and height of $\mathrm{H}=53 \mathrm{~cm}$. The packed area of the adsorption-filtration columns had a $\mathrm{DE}=4.7 \mathrm{~m}, \mathrm{DI}=4.4 \mathrm{~cm}$ and $\mathrm{H}=30 \mathrm{~cm}$. The upper and lower area of adsorption-filtration columns presented $\mathrm{DI}=4.4 \mathrm{~cm}, \mathrm{DE}=4.7 \mathrm{~cm}$ and $\mathrm{H}=$ $18-5 \mathrm{~cm}$. In addition, the modular plant had the accessories listed in Table 7.

Table 7. Accessories incorporated in the modular adsorption filtration plant

\begin{tabular}{|c|c|c|}
\hline \multirow{2}{*}{ Accessories } & \multicolumn{2}{|c|}{ Quantity } \\
\cline { 2 - 3 } & PVC (1 in) & CPVC (0.5 in) \\
\hline Codo & 6 & 10 \\
\hline Union & --- & 1 \\
\hline Tee & 1 & 5 \\
\hline Ball valve & 3 & 4 \\
\hline Gate valve & --- & 4 \\
\hline Foot valve & 1 & --- \\
\hline Pipe & $3.5(\mathrm{~m})$ & $4(\mathrm{~m})$ \\
\hline Pump & --- & --- \\
\hline
\end{tabular}

\subsection{Adsorption unit calibration}

The calibration of the adsorption unit of the pilot plant for water treatment in continuous system (adsorption - filtration) was carried out by varying the flow rate between $0.4,0.5$ and $06 \mathrm{~mL} \mathrm{~s}^{-1}$ and the height of the packed bed in the range between 5,10 and $15 \mathrm{~cm}$ during $180 \mathrm{~min}$. The removal percentage was obtained using equation 7 [17].

$$
\% R=\frac{C_{i}-C_{f}}{C_{i}} \square 100
$$

\subsection{Influence of flow rate and bed height}

Reduction in column exhaustion or saturation and residence time due to unsatisfactory use of the adsorption bed is a common phenomenon each time higher or extravagant flow rates are used in column adsorption processes [18]. Por lo anterior, se determinó la influencia del en las columnas de adsorción mediante 10 experimentaciones aleatorias, haciendo circular una solución contaminada con azul de metileno a 100 ppm y pH 5 por 180 min, variando a su vez la altura del lecho empacado, obteniendo como resultado la Fig. 3a.

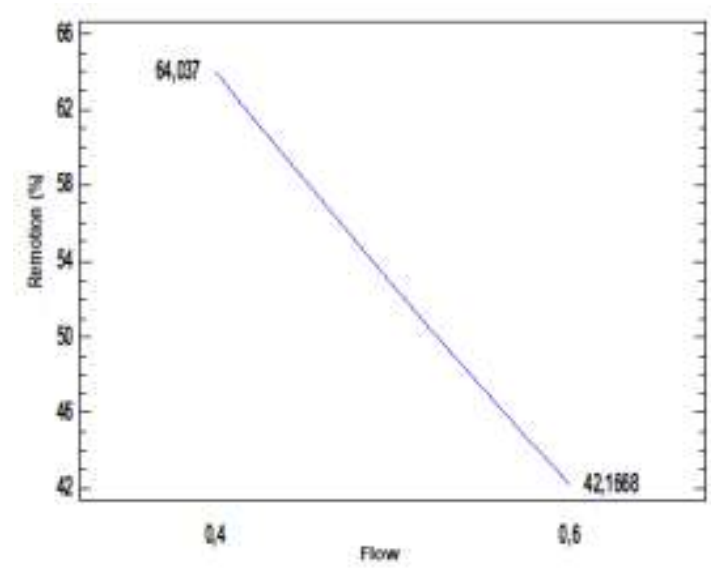

(a)

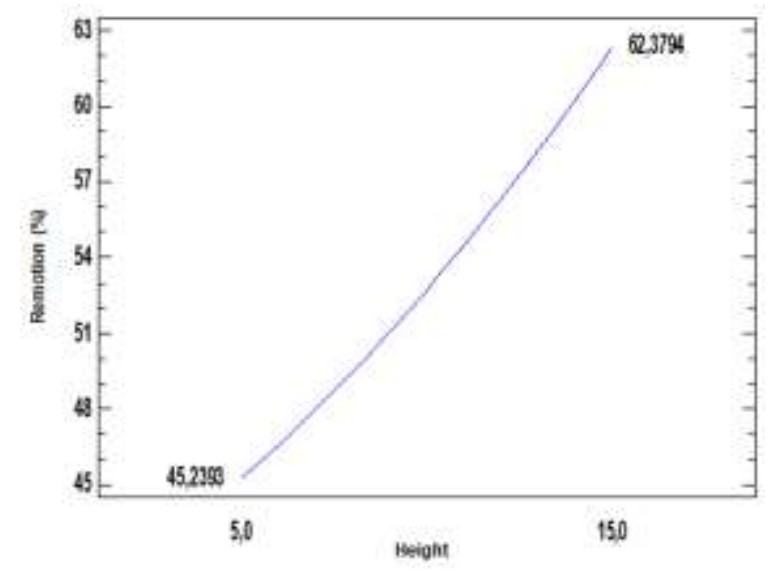

(b)

Figure 3. Influence on adsorption of (a) flow rate and (b) bed height. 
It was found that as flow decreases, the removal percentage increases, coinciding with previous research results in fixed-bed column biosorption systems for different heavy metals, using different adsorbent materials. This phenomenon could be due to the fact that at a slower rate of flow, the contact time between the methylene blue solution and activated carbon increases, which causes the contaminant to be trapped in the pores of the adsorbent. The increase in bed height of the adsorption columns results in an increase in the breaking point as well as the adsorbent's burnout time. This is due to an increase in the amount of adsorbent in the column which translates into an increase in the service area [19]. El efecto de la altura del lecho en la adsorción de azul de metileno usando carbón activado comercial se observa en la Fig. 3b. Se varió la altura del lecho aleatoriamente entre 5,10 y $15 \mathrm{~cm}$. It was obtained that the greater the quantity of adsorbent in the column there was greater percentage of removal being the height of $15 \mathrm{~cm}$ the one that presented better performance with respect to the other tested values, reflecting that this variable is important because the greater the height, increases the residence time since it is in the region of adsorption of the column that provided ample time for the diffusion or interaction of the molecules of solute with the adsorbent, y por ende mayor volumen del efluente en el lecho, aumentando asi la remocion del adsorbato en el proceso, obteniendo los mejores resultados, coherente con lo reportado por [20].

\subsection{Statistical analysis of variance}

Table 8 shows the values for each of the estimated effects and interactions of the independent variables, as well as the standard error obtained from the analysis of variance (ANOVA) carried out with the help of the software STATGRAPHICS Centurion XVI. II. The analysis of variance was carried out in order to establish the statistical significance of each variable and its effect on the process, comparing its mean square against an estimation of the experimental error; in this way, the significant parameters in the process of adsorption of AM with activated carbon are evaluated. For this, a 95\% confidence level was established (maximum permissible error 5\%), therefore effects or parameters with an error (P-value) of less than 0.05 are accepted as significant.

Table 8. Variance analysis for the removal percentage of methylene blue with activated carbon

\begin{tabular}{|l|l|l|l|}
\hline \multirow{2}{*}{ Average effect } & \multicolumn{1}{|c|}{ Estimated } & \multicolumn{1}{|c|}{ SS } & \multicolumn{1}{c|}{ V.I.F. } \\
\cline { 2 - 4 } & 52.74 & 5.81019 & \\
\hline A: Height & 17.1401 & 5.81019 & 1.0 \\
\hline B: Flow & -21.8702 & 5.8102 & 1.0 \\
\hline AA & 2.1387 & 7.68613 & 1.225 \\
\hline AB & 4.54 & 8.21685 & 1.0 \\
\hline BB & 0.723793 & 7.68619 & 1.225 \\
\hline
\end{tabular}

It is observed that the most influential variable in the unit adsorption operation is height, which affects positively. The least influential variable is the flow rate, which affects negatively as can be seen in the Pareto diagram in Fig. 13: 


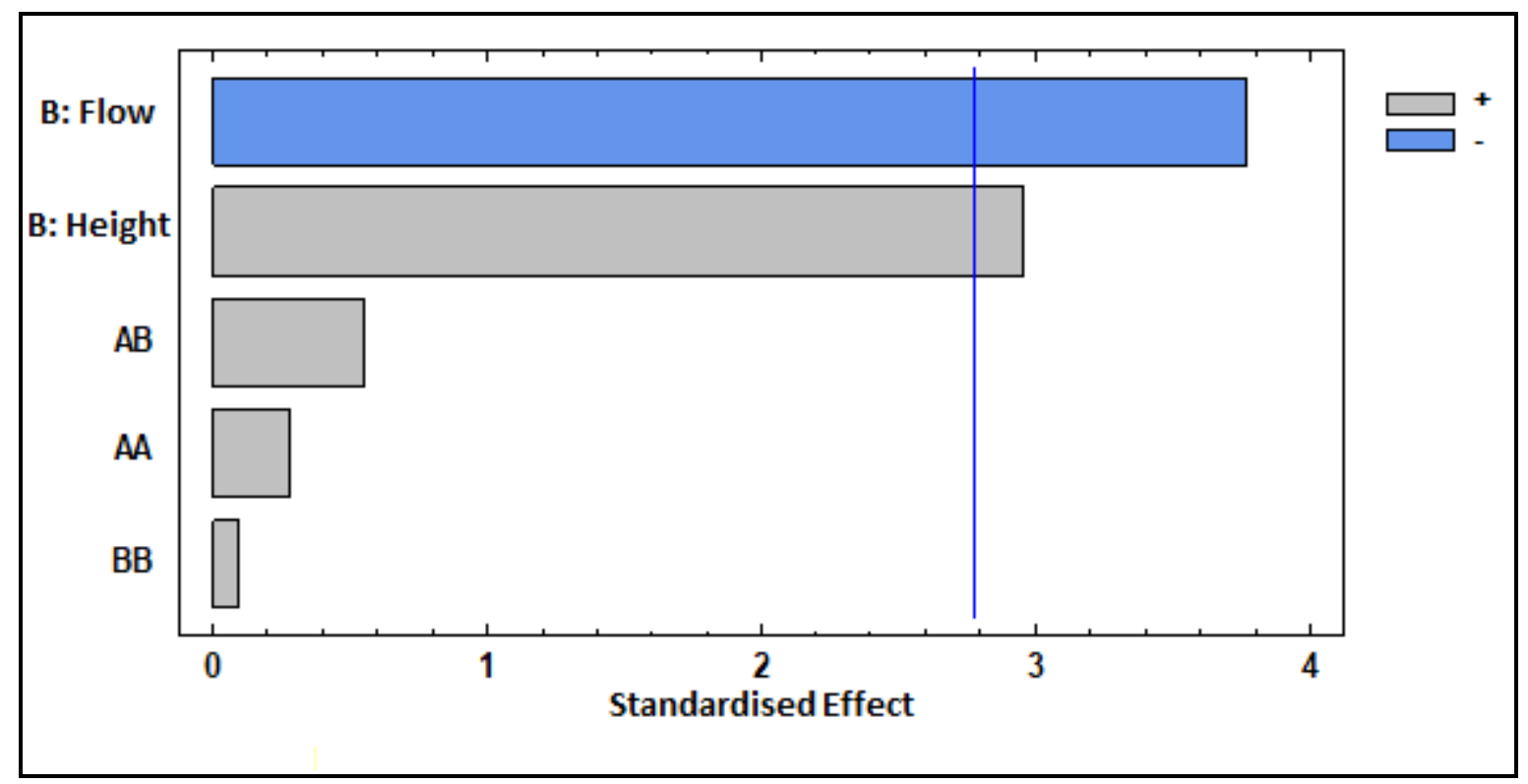

Figure 4. Adsorption Unit Operation Pareto Diagram

\subsection{Optimal configuration of operating parameters}

It was determined that the optimal operating conditions established for performing biosorption tests in continuous system are: bed height $15 \mathrm{~cm}$ and flow rate $0.4 \mathrm{~mL} / \mathrm{s}$. This combination of levels, which maximize removal efficiency, is used in the construction of the rupture curve. Subsequently, the RSM was applied to the optimal conditions, obtaining Equation 8 where $\mathrm{R}(\%)$ is the removal percentage, A is the height $(\mathrm{cm})$, B is the flow $\left(\mathrm{mL} \mathrm{s}^{-1}\right)$. Subsequently, the data was plotted, obtaining the response surface graph, combining the three main factors and the value of the response variable in all the resulting combinations as shown in figure 5.

$\% R=126.3-1.41147 \square A-190.94 \square B$

With equation 8 we obtained a correlation coefficient $\mathrm{R}^{\wedge} 2=0.95$ and an estimated standard error $\mathrm{SS}=2.9$; using this model we obtained estimated values as well as 10 response surfaces shown in Table 9 .

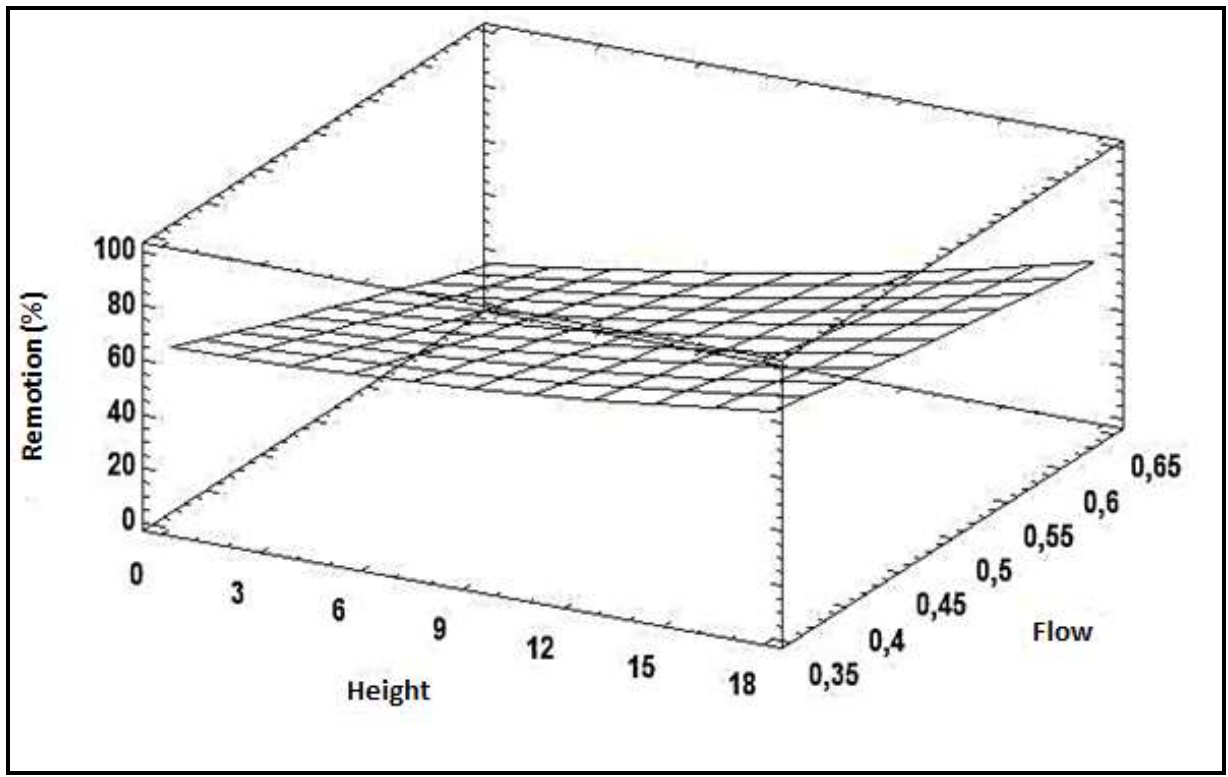

Figure 5. Estimated response area (influence of filling height and flow rate) 
The percentage of removal of the adsorption column in the pilot plant of water treatment in a continuous system is highly influenced by the independent variables (high-flow) of operation in the present investigation, thus observing that the higher the height of the packed bed and the lower the flow rate, the percentage removed increases its value, as can be seen in Figure 5.

Table 9. Estimated experimental values in unit adsorption operation

\begin{tabular}{|l|l|l|l|l|}
\hline & Observados & Ajustados & Inferior 95,0\% & Superior 95,0\% \\
\hline Fila & Valores & Valores & para Media & para Media \\
\hline 1 & 39,03 & 32,3961 & 14,3603 & 50,4319 \\
\hline 2 & 64,4 & 58,8063 & 40,7704 & 76,8421 \\
\hline 3 & 53,5 & 52,74 & 36,6083 & 68,8717 \\
\hline 4 & 51,98 & 52,74 & 36,6083 & 68,8717 \\
\hline 5 & 60,01 & 54,0762 & 36,0404 & 72,112 \\
\hline 6 & 61,73 & 66,9987 & 48,9628 & 85,0345 \\
\hline 7 & 31,5 & 37,9993 & 19,9635 & 56,0351 \\
\hline 8 & 36,5 & 42,7588 & 24,723 & 60,7946 \\
\hline 9 & 76,3 & 71,4064 & 53,3706 & 89,4422 \\
\hline 10 & 63,9 & 68,9283 & 50,8925 & 86,9641 \\
\hline
\end{tabular}

Within the range of values implemented in the adsorption unit operation in the pilot plant of continuous water treatment, it is guaranteed that at the highest amount of the packed bed height and the lower flow rate implemented, a higher percentage of removal would be obtained, according to the results obtained in the optimal operating value of the system of $78.6464 \%$, so it is observed that outside these values, will not obtain a better performance of the system. Coinciding with the proposed Hormaza et al., [9].

\subsection{Modelling the rupture curve}

The efficiency of a packed bed column is established by the rupture curve concept, which is a feature that makes it possible to determine the service time and thus establish the dynamic response of the column. In order to determine the model that best fits the system, a curve of rupture was made with the operating conditions that proceeded to carry out the optimal operation of the pilot plant; according to the results obtained in the experiments, these conditions were: initial concentration of the aqueous solution $100 \mathrm{ppm}$; flow rate of 24 $\mathrm{mL} \mathrm{min}^{-1}$; bed height of $15 \mathrm{~cm}$ (168 $\mathrm{g}$ of activated carbon).

Under these conditions, a last experiment was carried out in which retained concentration data $\left(\mathrm{C}_{\mathrm{t}} / \mathrm{C}_{\mathrm{o}}\right)$ were obtained. The performance of the pollutant retained in activated carbon bed is expressed in terms of the variation of the initial concentration with respect to time, $C_{t} / C_{0}$, which is a function of the volume of the effluent at a given height, thus generating the respective curve [21, 22]. In order to analyze column performance, the kinetic model of experimental data was adjusted to the Adams-Bohart, Yoon-Nelson and Thomas models (Table 10).

Table 10. Models for modeling of adsorption rupture curves

\begin{tabular}{|c|c|c|}
\hline Model & Equation & Parameter \\
\hline $\begin{array}{l}\text { Bohart- } \\
\text { Adams }\end{array}$ & $\ln \frac{C_{t}}{C_{i}}=K_{A B} C_{i} T-K_{A B} N_{0} \frac{z}{v}$ & $\begin{array}{l}\mathrm{C}_{\mathrm{t}}, \mathrm{C}_{\mathrm{i}}, \mathrm{K}_{\mathrm{BA}}, \mathrm{N}_{0}, v, \mathrm{Z} \text { are the concentration in } \\
\text { time } \mathrm{t} \text {, initial concentration, kinetic constant } \\
(\mathrm{L} \mathrm{mg} h) \text {, biosorption capacity }\left(\mathrm{mg} \mathrm{L}^{-1}\right) \text {, } \\
\text { linear flow velocity }\left(\mathrm{cm} \mathrm{h}^{-1}\right) \text { and bed height } \\
(\mathrm{cm}) \text {, respectively. }\end{array}$ \\
\hline Thomas & $\ln \left(\frac{C_{i}}{C_{t}}-1\right)=\frac{K_{T} q_{0} m}{F}-K_{T} C_{i} t$ & $\begin{array}{l}\text { Where } \mathrm{K}_{\mathrm{T}}, \mathrm{q}_{0} \text { and } \mathrm{F} \text { are constant velocity }(\mathrm{L} \\
\left.\mathrm{mg}^{-1} \mathrm{~h}^{-1}\right) \text {, the absorption capacity of metals } \\
\left(\mathrm{mg} \mathrm{g}^{-1}\right) \text { and frequency }\left(\mathrm{L} \mathrm{h}^{-1}\right) \text {, respectively. }\end{array}$ \\
\hline Yoon-Nelson & $\ln \left(\frac{C_{t}}{C_{i}-C_{t}}\right)=K_{Y N} t-K_{Y N} \tau$ & $\begin{array}{l}\text { Where } \mathrm{K}_{\mathrm{Y}} \text { is the velocity constant }\left(\mathrm{h}^{-1}\right) \text { and } \tau \\
\text { the time required for } 50 \% \text { advance adsorbate } \\
\text { (h). }\end{array}$ \\
\hline
\end{tabular}


The Thomas model was one of the most commonly used models to describe column performance and predict the adsorption rupture curve and its main limitation is that its derivation is based on second-order kinetics and considers that biosorption is not limited by chemical reaction but controlled by matter transfer at the interface [20]. Yoon-Nelson assumes that the rate of decrease in adsorption probability for each adsorbate molecule was proportional to the probability of adsorbate and the probability of adsorbate advancement in adsorbent [23].

Table 11. Comparison of the fitting parameters of the kinetic models of Adams-Bohart, Yoon-Nelson and Thomas for the adsorption of methylene blue on activated carbon

\begin{tabular}{|c|c|c|}
\hline Model & Parameter & Value \\
\hline Adams-Bohart & $\mathrm{k}_{\mathrm{AB}}\left(\mathrm{L} \mathrm{min}^{-1} \mathrm{mg}^{-1}\right)$ & 0.00002797 \\
\cline { 2 - 3 } & $\mathrm{N}_{0}\left(\mathrm{mg} \mathrm{L}^{-1}\right)$ & 14103.12 \\
\cline { 2 - 3 } & $\mathrm{SS}$ & 0.001361 \\
\cline { 2 - 3 } & $\mathrm{R}^{2}$ & 0.951 \\
\hline \multirow{4}{*}{ Thomas } & $\mathbf{k}_{\mathrm{Th}}\left(\mathbf{m L ~ m i n}^{-1} \mathbf{~ m g}^{-1}\right)$ & 0.087809 \\
\cline { 2 - 3 } & $\mathrm{Q}_{0}\left(\mathrm{mg} \mathrm{g}^{-1}\right)$ & 15.37820 \\
\cline { 2 - 3 } & $\mathrm{SS}$ & 0.00582559 \\
\cline { 2 - 3 } & $\mathrm{R}^{2}$ & 0.959 \\
\hline \multirow{5}{*}{ Yoon-Nelson } & $\mathrm{K}_{\mathrm{YN}}\left(\mathrm{min}^{-1}\right)$ & 0.00449208 \\
\cline { 2 - 3 } & $\tau\left(\mathrm{min}^{-1}\right.$ & 95.0343455 \\
\cline { 2 - 3 } & $\mathrm{SS}$ & 0.00903853 \\
\cline { 2 - 3 } & $\mathrm{R}^{2}$ & 0.9664 \\
\hline
\end{tabular}

The Adams-Bohart model assumes that adsorption rate is proportional to the residual capacity of the solid and the concentration of the retained species and is used to describe the initial part of the rupture curve $[24,25]$. The values of the parameters of the previously mentioned models and the corresponding ones: sum of errors (SS) and correlation coefficient $\left(\mathrm{R}^{2}\right)$ can be found in Table 11 and the graphs are shown in Figure 6.

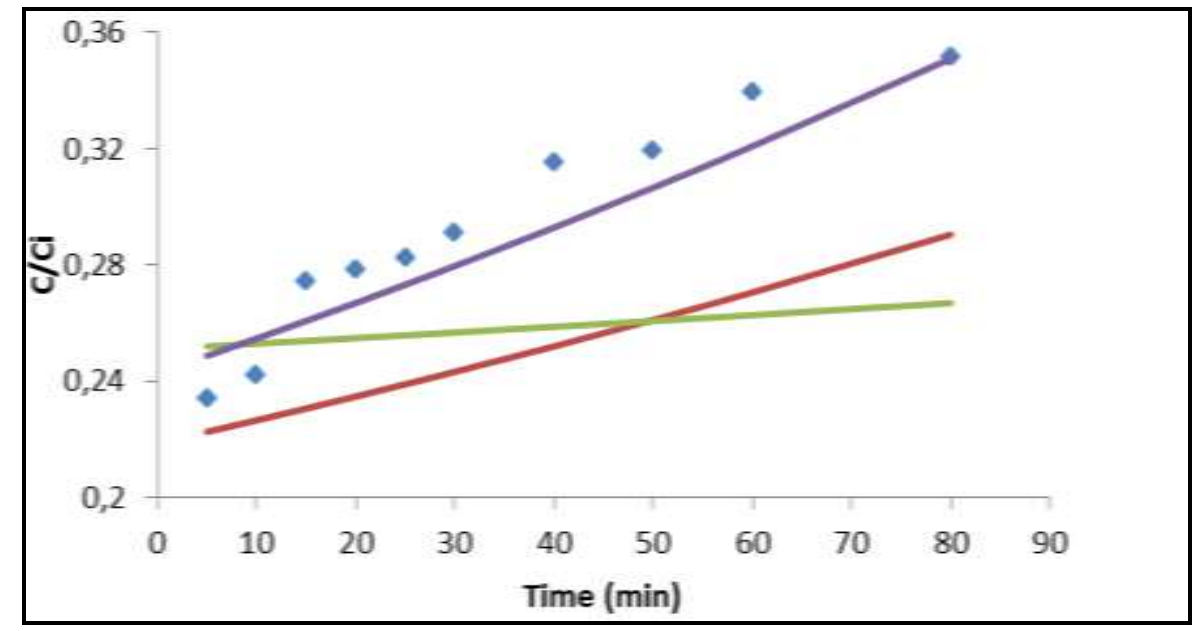

Figure 6. Graphic adjustment of the rupture curve fit to Yoon-Nelson, Thomas and Adams-Bohart models for the adsorption of methylene blue on activated carbon. $(\bullet)$ Experimental data, $(-)$ AdamsBohart, $(-)$ Thomas, $(-)$ Yoon-Nelson

Table 11 shows that the three models used properly fitted the experimental adsorption data of methylene blue on activated carbon, Yoon-Nelson's being the one that presented a better arrangement with $\mathrm{R}^{2}=0.9664$, which is graphically corroborated in Figure 6 consistent with what was found by Afroze et al., [26] and Djelloul and Hamdaoui [27]. The adjustment to this model assumes that the driving force of the adsorption process is due to second-order kinetics with irreversible reaction. It is also an adjustment is appropriate for constant flow in column without axial dispersion as reported by Tejada-Tovar et al., [28]. 


\subsection{Influence of stratification}

The calibration of the filtering unit of the pilot plant for water treatment in continuous system (adsorption - filtration) consisted in maintaining a constant flow rate of $0.4 \mathrm{~mL} / \mathrm{s}$, for $300 \mathrm{~min}(5 \mathrm{~h})$, height of the packed bed of $20.5 \mathrm{~cm}$ where extreme values were taken to the optimal ones (stratification), to check the efficiency of the same ones. Three tests were carried out: Experimentation 1, Experimentation 2 and Experimentation 3, with the last start-up under optimal conditions in both columns, obtaining the data of removal percentages reported in Table 12. Three tests were carried out: Experimentation 1, Experimentation 2 and Experimentation 3, with the last start-up under optimal conditions in both columns, obtaining the data of removal percentages reported in Table 12.

Table 12. Percentage of removal experiments filtration experiments

\begin{tabular}{|c|c|c|}
\hline \multicolumn{3}{|c|}{ Remotion percentage (\%) } \\
\hline Experimentation & Experimentation & Experimentation \\
$\mathbf{1}$ & $\mathbf{2}$ & $\mathbf{3}$ \\
\hline 83.94 & 90.56 & 96.03 \\
\hline 83.56 & 89.56 & 91.69 \\
\hline 83.53 & 88.06 & 90.84 \\
\hline 82.09 & 88.00 & 89.63 \\
\hline 81.53 & 85.34 & 88.41 \\
\hline 80.97 & 83.59 & 86.59 \\
\hline 80.03 & 83.38 & 85.47 \\
\hline 77.94 & 82.53 & 83.53 \\
\hline 77.53 & 79.16 & 80.50 \\
\hline 75.53 & 77.88 & 78.69 \\
\hline 74.41 & 77.81 & 75.75 \\
\hline 69.19 & 67.81 & 74.97 \\
\hline 66.56 & 66.25 & 69.09 \\
\hline
\end{tabular}

Stratification was the most influential variable in the system, behaving the column in the first run as a fast filter, but its removal percentage was reduced compared to other experiments. In the second experiment the filter obtained a good percentage of removal, but its behaviour is similar to that of a slow filter, therefore in experiment 3 the filter acted as fast and the highest percentage of removal was obtained, thus highlighting the importance of stratification. This can be corroborated as reported by Canepa et al., [15], which demonstrates the importance of the different heights that can be given to filter media, as well as Long et al., [29] demonstrated the influence of stratification when applying filtration.

\subsection{Filtration kinetics modeling}

To determine the model that best fits the system, a removal percentage vs. $t$ (min) curve was made with the operating conditions that gave the best response value, which are: initial turbidity $=32 \mathrm{NTU}$, flow rate $\mathrm{Q}=24 \mathrm{~mL} \mathrm{~min}{ }^{-1}$, bed height $\mathrm{H}=23.3 \mathrm{~cm}$ and stratification of $6.7 \mathrm{~cm}$ sand and $16.6 \mathrm{~cm}$ anthracite. Turbidity removal tests were performed using a sand-anthracite filter, modeling experimental filtration data using the mathematical models of Mintz and Krishtul, Deb and Adin and Rebhun (Table 13). 
Table 13. Models for the modeling of turbidity removal percentage curves by filtration

\begin{tabular}{|c|c|c|}
\hline Model & Equation & Parameter \\
\hline $\begin{array}{l}\text { Mintz y } \\
\text { Krishtul }\end{array}$ & $\begin{array}{l}-\frac{d C}{d L}=\lambda C-\frac{\alpha}{v} \sigma \\
(12)\end{array}$ & $\begin{array}{l}\text { Where } \alpha \text { is the detachment coefficient and } \mathrm{v} \\
\text { filtration speed. }\end{array}$ \\
\hline Deb & $\begin{array}{l}\frac{v}{P_{o}-\sigma d L}+\frac{d C}{d t}=-\lambda^{\prime} C \\
(13)\end{array}$ & $\begin{array}{l}\text { Where } v \text { is the filtration rate and } \lambda \text { modified } \\
\text { filtration coefficient }\left(t^{-1}\right) \text {. }\end{array}$ \\
\hline $\begin{array}{l}\text { Adin y } \\
\text { Rebhun. }\end{array}$ & $\frac{\partial C}{\partial L}=K_{1} C(F-C)-K_{2} \frac{\sigma}{K_{o}}(1-\sqrt{\sigma / F})^{3}$ & $\begin{array}{l}\text { Where } \sigma \text { is the specific deposit } \mathrm{i} \text {. e. volume } \\
\text { of solid deposited per unit of volume of the } \\
\text { filter medium }\left(\mathrm{mg} \mathrm{cm}^{-3}\right), t \text { the filtration time } \\
\text { in hours, } \mathrm{c} \text { is the concentration of particles } \\
(\mathrm{mg} \mathrm{cm}), \mathrm{V}=\mathrm{vt} \text { the average volume per } \\
\text { unit of filter area }\left(\mathrm{cm}^{3} \mathrm{~cm}^{-2}\right), \mathrm{L} \text { is the depth } \\
\text { of the filter bed in } \mathrm{cm}^{-3} n \text { is the filtration } \\
\text { speed }\left(\mathrm{m} \mathrm{h}^{-1}\right), \mathrm{K}_{\mathrm{o}} \text { is the hydraulic } \\
\text { conductivity of the clean medium }\left(\mathrm{cm} \mathrm{h}^{-1}\right) \text {, } \\
\mathrm{L} \text { is the depth of the filter bed in } \mathrm{cm}, n \text { is } \\
\text { the filtration speed }\left(\mathrm{m} \mathrm{h} \mathrm{h}^{-1}\right) \text {, Ko is the } \\
\text { hydraulic conductivity of the clean medium } \\
\left(\mathrm{cm} \mathrm{h}^{-1}\right) \text {. }\end{array}$ \\
\hline
\end{tabular}

The Mintz and Krishtul model, represented in equation 12, assumes that when the suspension is passed through a granular medium, the solid particles are retained in it by adhesion to the grains; however, these deposits are considered unstable, which is why they become detached as the race progresses and penetrate deeper and deeper into the filter. Therefore, the concentration of particles in each bed depends on the action of two opposing processes: the adhesion of floc to bed grains and the detachment or rupture of deposited material, due to the increase in water velocity over time in the pores; gradually the detached floc saturates all layers of the filter bed, thus the concentration of particles in the tributary of the filter begins to increase [15].

Table 14. Adjustment parameters of the Deb, Adin and Rebhun and Mintz and Krishtul filtration models using a continuous sand-anthracite bed

\begin{tabular}{|c|c|c|}
\hline Model & Parameter & Value \\
\hline \multirow{10}{*}{ Adin y Rebhun } & $\sigma\left(\mathrm{mg} \mathrm{cm}^{-3}\right)$ & 0.0033529 \\
\hline & $\alpha . \mathrm{K}_{2}\left(\mathrm{mg} \mathrm{cm}^{-3}\right)$ & 0.02134085 \\
\hline & $\lambda . \mathrm{K}_{1}\left(\mathrm{mg} \mathrm{cm}^{-3}\right)$ & 0.02965397 \\
\hline & $\mathrm{K}_{\mathrm{o}}\left(\mathrm{cm} \mathrm{h}^{-1}\right)$ & 7.36 \\
\hline & $\mathrm{C}\left(\mathrm{mg} \mathrm{cm}^{-3}\right)$ & 32 \\
\hline & $\mathrm{L}(\mathrm{cm})$ & 23.3 \\
\hline & $\mathrm{F}\left(\mathrm{mg} \mathrm{cm}^{-3}\right)$ & 0.41 \\
\hline & $\epsilon$ & 0.415 \\
\hline & SS & 0.001957294 \\
\hline & $\mathrm{R}^{2}$ & 0.95541699 \\
\hline \multirow{5}{*}{ Deb } & $\lambda\left(\mathrm{t}^{-1}\right)$ & 0.0412 \\
\hline & $\sigma\left(\mathrm{mg} \mathrm{cm}^{-3}\right)$ & 0.0034 \\
\hline & $\rho_{\mathrm{s}}$ & 0.801 \\
\hline & SS & 0.00028145 \\
\hline & $\mathrm{R}^{2}$ & 0.984950968 \\
\hline \multirow{4}{*}{ Mintz y Krishtul } & $\alpha$ & 0.0213 \\
\hline & $\sigma\left(\mathrm{mg} \mathrm{cm}^{-3}\right)$ & 0.0046 \\
\hline & SS & 0.007532319 \\
\hline & $\mathrm{R}^{2}$ & 0.880381354 \\
\hline
\end{tabular}


The equations proposed by Deb, with proven applicability in Fuller's soil suspensions, consider local increases in concentration over time. The Adin and Rebhun model develops the possibility of describing changes in particle concentration in water effluent, using empirical coefficients determined for each type of effluent concentration. Table 14 shows the adjustment parameters of the filter models with their respective $\mathrm{R}^{2}$ and statistical error (SS) and the graphs in Fig. 7. In Table 14 it can be seen that the Deb and Adin and Rebhun models adequately adjusted the experimental turbidity removal data, being Deb the one that presented the best results with an $\mathrm{R}^{2}=0.98$ and minimum statistical error.

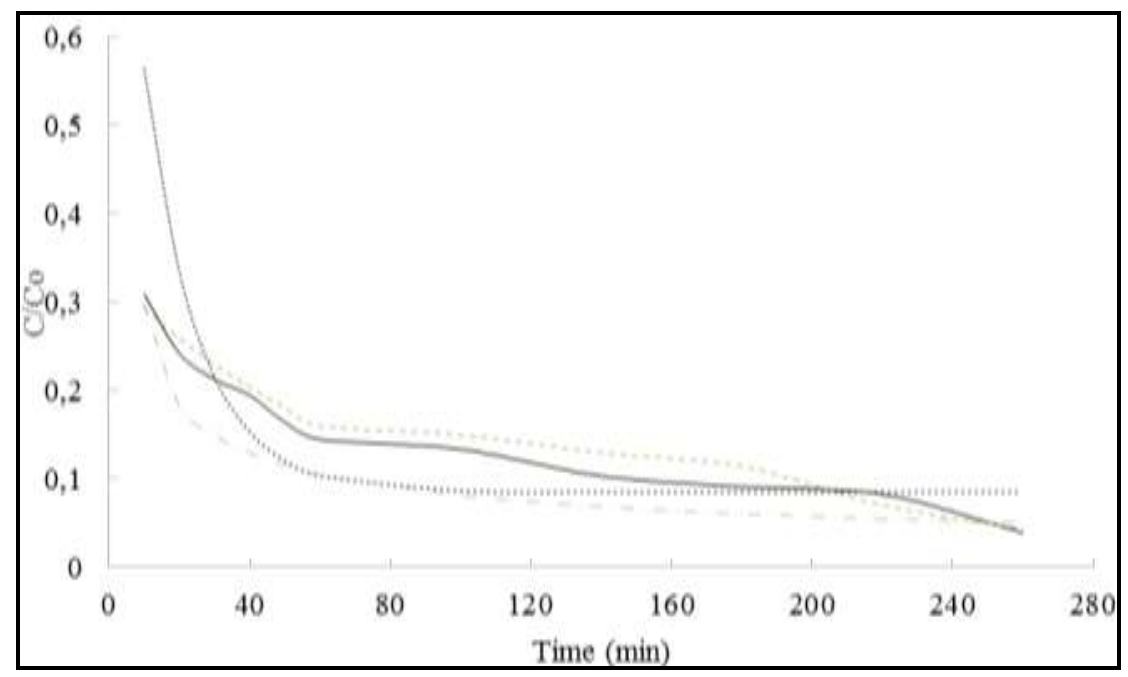

Figure 7. Comparison of experimental data and mathematical models. ( - ) Experimental data, ( $\quad$ ) Mintz and Krishtul , (-..) DEB, (-.- ) Adin

\section{Conclusions}

A modular adsorption-filtration plant was built to remove methylene blue and turbidity present in solution, respectively. It was found that the most influential design parameters were length, column diameter and flow rate, since they allow the calculation of height, area, minimum operating flow, as well as the volume of effluent to be treated in the modular plant for continuous system water treatment. When performing the methylene blue adsorption tests, it was obtained that the parameter that most affects the adsorption capacity is the feed flow rate, while the parameter that most influences the percentage of dye removed is the filling height, establishing the response surface methodology and optimum adsorption conditions efficiently, adjusting the experimental data to the Yoon-Nelson model with $\mathrm{R}^{2}=0.97$ and a removal rate of $79.74 \%$. The most influential parameter in the filtration system was the stratification of the bed, proving that the rapid filtration rate under the conditions of filling heights in the established range significantly influences, with the DEB equation being the one that best adjusts the dynamic behavior of this process with $\mathrm{R} 2=0.98$ and a removal percentage of $95.82 \%$. The use of a modular filtration-adsorption system for removal of methylene blue and turbidity using activated carbons and a sand-gravel-anthracite filter, respectively, is an economical alternative to conventional water treatments.

\section{References}

1. Marrakchi F, Khanday WA, Asif M, Hameed BH. "Cross-linked chitosan/sepiolite composite for the adsorption of methylene blue and reactive orange 16", Int J Biol Macromol, vol. 93, no. (Pt A), pp. 1231-12399, 2016.

2. Moreno A, Figueroa D, Hormaza A. "Adsorción de azul de metileno sobre cascarilla de arroz", Rev. Producción+Limpia, vol. 7, no. 1, pp. 9-18, 2012.

3. Altundag, H., Bina, E., Altınt1g, E. "The levels of trace elements in honey and molasses samples that were determined by ICP-OES2, Biol. Trace Elem. Res, vol. 170, pp. 508-514, 2016.

4. Moura-Bernardes, A. "Drinking Water Treatment", In Encyclopedia of Membranes. Springer Berlin Heidelberg, p. 588-591. 2016. 
5. Florez Ordeñana LM, Petkova SV. "Metodología de filtración experimental con base en filtros de lecho poco profundo", In Congreso Interamericano de Ingeniería Sanitaria y Ambiental, vol. 25, (pp. 1-6), AIDIS, 1972.

6. Miller DG. Filtración con arena y antracita. "Caso práctico en el Reino Unido. Asociación de Investigación sobre el agua", Conferencia sobre la filtración con arena y antracita. Universidad de Reading, pp. 299-307, 1972.

7. Villada Y, Hormaza A, Casis N. "Uso de la cascarilla de arroz para la remoción de azul de metileno en columnas de lecho empacado", Tecno Lógicas, vol. 17, no. 33, pp. 43-54, 2014.

8. García JC, Pérez P, Cachaza JM, García Roig M. "Un estudio de planta piloto de los procesos de filtración y adsorción de agua a través de carbones activados granulares: un estudio comparativo. 2013.

9. Hormaza A, Villada Y, Orrego L. "Remoción de azul brillante mediante columnas empacadas usando tuza de maíz", Revista de Investigación Agraria y Ambiental, vol. 5, no. 1, pp. 57-68, 2014.

10. Islam, S.; Ahmed, K.; Raknuzzaman, M.; Al-Mamun, H.; Islam, M.K. "Heavy metal pollution in surface water and sediment: A preliminary assessment of an urban river in a developing country", Ecological indicators, vol. 48, pp. 282-291, 2015.

11. D. Angin, E. Altintig, T. E. Köse. "Influence of process parameters on the surface and chemical properties of activated carbon obtained from biochar by chemical activation", Bioresource Technology, vol. 148, pp. 542-549, 2013.

12. Clavijo-Penagos JA. Sobre las reacciones de eliminación de compuestos contaminantes de aguas por fotocatálisis con TiO2/UV: caso azul de metileno", Rev. Elementos, vol. 3, no. 3, pp. 146-156, 2013.

13. González, J. R., Alcaraz, J. L. G., Angulo, G. V., Macías, A. A. M., Valdivieso, I. C., Rodríguez, J. R., Martínez, R. R. "Modelación del proceso de transferencia de masa en columnas de lecho fijo de la bioadsorción del Cr (VI) usando transformadas de Laplace", CULCyT, vol. 41, pp. 106-131, 2015.

14. Perea L, Torres P, Cruz C. "Influence of the Flow Control (Declining Rate - Constant Rate) on the Filtration Process in Drinking Water Treatment", Ingeniería y Universidad, vol. 8, no. 2, pp. 217-234, 2014

15. Canepa L, Maldonado V, Barrenechea A, Aurazo M. Capítulo 7: Teoría de Filtración del agua. In Tratamiento de agua para consumo humano: Plantas de filtración rápida. Manual I: teoría. Tomo II. Lima: CEPIS; p. 296 - 300. 2004.

16. Lopez F, Achaerandio M, Ferrando C, Labbé M, Lira E, Pandolfi E, Salazar F. Filtracion estabilizante en vinos blancos: una alternativa para la bentonita. 27 reunión del Grupo de Trabajo de Experimentación en Viticultura y Enología. Madrid, España. 2014.

17. Tejada-Tovar, C., Herrera, A., Núñez-Zarur, J. "Remoción de plomo por biomasas residuales de cáscara de naran (Citrus sinensis) y zuro de maíz (Zea mays)”, Rev. U.D.C.A Act. \& Div. Cient, vol. 19, no. 1, pp. 169-178, 2016.

18. Chowdhury, Z.Z., Zain, S.M., Rashid, A.K., Rafique, R.F., Khalid, K. "Breakthrough curve analysis for column dynamics sorption of $\mathrm{Mn}(\mathrm{II})$ ions from wastewater by using mangostana garcinia peel-based granular-activated carbon", J. chem, pp. 1-8, 2013.

19. Atua, M., Hameed, B.H. "Chitosan-clay composite as highly effective and low-cost adsorbent for batch and fixed-bed adsorption of methylene blue", Chem. Eng. J, vol. 237, pp. 352-361, 2014.

20. Calero, M., Blázquez, G., Hernáinz, F., Ronda, A. y Martín, M. "Biosorción de cobre con corteza de pino en columna de lecho de fijo: optimización de las variables del proceso", Afinidad, vol. 69, no. 559, pp. 175-184, 2012.

21. Gong, J.L., Zhang, L., Jiang, Y., Zeng, G.M., Cui, Z.H., Liu, K., Deng, C.H., Niu, Q.Y., Deng, J.H., Huan, S.Y. "Continuous adsorption of $\mathrm{Pb}(\mathrm{II})$ and methylene blue by engineered graphite oxide coated sand in fixed-bed column", Appl. Surf. Sci, vol. 330, pp. 148-157, 2015.

22. Lara, J., Tejada-Tovar, C., Villabona-Ortíz, A., Arrieta, A. "Adsorción de plomo y cadmio en sistema continuo de lecho fijo sobre residuos de cacao", Ingeniería y Competitividad, vol. 29, no. 2, pp. 111$122,2016$.

23. Ghribi, A. y Chlendi, M. "Modeling of Fixed Bed Adsorption: Application to the Adsorption of an Organic Dye", Asian J. Textile, vol. 1, 4, pp. 161-171, 2011.

24. Crini, G. y Badot, P. "Sorption processes and pollution: Conventional and non-conventional sorbents for pollutant removal from wastewaters", Besançon: Presses universitaires de Franche-Comté, 45p, 2010. 
25. Rojas, H., Guerrero, D., Vásquez, O. y Valencia, J. "Aplicación del Modelo de Bohart y Adams en la Remoción de Mercurio de Drenajes de Minería por Adsorción con Carbón Activado", Información tecnológica, vol. 23, no. 3, pp. 21-32, 2012.

26. Afroze, S., Sen, T. K., \& Ang, H. M. "Adsorption performance of continuous fixed bed column for the removal of methylene blue (MB) dye using Eucalyptussheathiana bark biomass", Research on Chemical Intermediates, vol. 42, no. 3, pp. 2343-2364, 2016.

27. Djelloul, C., Hamdaoui, O. "Dynamic adsorption of methylene blue by melon peel in fixed-bed columns", Desalination and Water Treatment, vol. 56, no. 11, pp. 2966-2975, 2015.

28. Tejada-Tovar, C.N., Villabona-Ortíz, A., Alvarez-Bajaire, G., Jattin-Torres, L., Granados-Conde, C. "Influencia de la altura del lecho sobre el comportamiento dinámico de columna fijo en la biosorción de mercurio", TecnoLógica, vol. 20, no. 40, pp. 71-81, 2017.

29. Long Y, Lei D, Ni J, Ren Z, Chen C, Xu H. "Packed bed column studies on lead (II) removal industrial wastewater by modified Agaricus bisporus", Bioresource Technology, vol. 152, pp. 457-463, 2014. 